Atanasova B, Graux J, El-Hage W, Hommet C, Camus V, Belzung C. Olfaction: a potential cognitive marker of psychiatric disorders. Neuroscience \& Biobehavioral Reviews 2008;32(7):1315-1325. doi:10.1016/j.neubiorev.2008.05.003

\title{
Olfaction: a potential cognitive marker of psychiatric disorders
}

Boriana Atanasova a, Jérôme Graux ${ }^{\mathrm{b}}$, Wissam El Hage ${ }^{\mathrm{a}, \mathrm{b}}$, Caroline Hommet ${ }^{\mathrm{a}}$, Vincent Camus ${ }^{a, b}$, Catherine Belzung ${ }^{\text {a, } 1}$

\author{
a INSERM U-930 FRE CNRS 2448, Université François Rabelais Tours, Parc Grandmont, 37200 Tours, France \\ ${ }^{\mathrm{b}}$ Clinique Psychiatrique Universitaire, CHRU de Tours, 37044 Tours, France
}

\begin{abstract}
Cognitive deficits are well documented in psychiatric disorders, particularly in schizophrenia and depression. Cognitive activity roots in perceptions. However, research on sensorial alterations in psychiatric conditions has mainly focused on visual or auditory processes and less on olfaction. Here, we examine data on olfactory deficits in psychiatric patients using a systematic review of recent publications. Schizophrenic patients are mainly characterized by no reliable change in odour sensitivity and by a deficit in odour identification, recognition and discrimination. Depressed patients principally exhibit a deficit in the hedonic aspects of this perception, even if, in some case, alterations in sensitivity or identification are also found. Changes in odour perception are also found in dementia and in some neurodegenerative disease, but in this case alterations concern all aspects of the sensorial experience (detection threshold, identification and recognition). Taken together, these data indicate that olfactory abnormalities might be a marker of psychiatric conditions, with a specific pattern for each disease.
\end{abstract}

Key words: olfaction - cognitive bias - depression - schizophrenia - marker

\section{Introduction}

About $15 \%$ of the global burden of worldwide diseases is attributed to mental disorders (Prince et al., 2007) that are characterized by modified patterns of behaviours, perceptions, cognition, emotions. Depending on their clinical characteristics, psychiatric disorders have various but sometimes severe impact on social skills, relationships, wellbeing, and quality of life. Consequently, they are potentially highly disabling conditions. The understanding of pathophysiological mechanisms of psychiatric disorders is usually addressed at several different levels. Developments in structural and functional neuroimaging techniques have highlighted the potential neuroanatomical substrates of diseases (Abi Dargham et al., 1996; Yathan and Malhi, 2003; Hajek et al., 2005; Campbell and MacQueen, 2006; Gur et al., 2007), while clinically significant impact of drugs modifying neurotransmission gives strong support to the monoamine hypothesis of several psychiatric disorders (Hindmarch, 2002), especially considering psychiatric disorders as the consequences of excess or lack of neurotransmission. Nevertheless, mechanisms of action of psychotropic drugs such as antidepressants or antipsychotics are not fully understood, and it is now widely admitted that apart to enhance or limit neurotransmission, they induce also intracellular effects (Hindmarch, 2002; Yamada and Higuchi, 2002) and that their clinical efficacy can be mediated by neuroplasticity (Malberg et al., 2000; McEwen et al., 2002; Santarelli et al., 2003; Jiang et al., 2005; Yoshimizu and 
Chaki, 2004). As being a construct of brain activity and related to specific brain areas, cognition has been considered as reflecting cerebral functioning and its modification as a potential mechanism underlying psychiatric disorders. At this time, most of the data on cognitive deficits in psychiatric disorders have focused on memory or executive dysfunctions. This has been particularly well documented in schizophrenia (Dickinson et al., 2004) or in mood disorders (Chamberlain and Sahakian, 2006), in which cognition is also a major therapeutic target (Tukington et al., 2006; Kuyken et al., 2007). In fact cognition gathers a wide range of mental processes like memory, attention, thought process, decision making, language, executive and motor performance. Representations from which action, goal directed behaviour and adaptation to the environment are built, emerge from cognitive activity that roots in sensorial (Mesulan, 1998) and emotional perceptions (Philipps et al., 2003). Until now, researches on cognitive dysfunctions in psychiatric disorders have mainly focused on processes supported by visual or auditory inputs, and less has been done on cognitive functions that are related to olfactory stimuli. Even so, odours have been shown to have a high potential of emotional remembering. This could be explained by the partial overlap of both olfaction and short term memory neuroanatomic substrates (Richardson and Zucco, 1989). Olfactory perception can be experimentally assessed with good reliability by the measurement of several characteristics such as identification of odour, intensity and detection threshold as well as by emotional response (hedonic state) (Alaoui-Ismaili et al., 1997).

Olfactory dysfunction has indeed been investigated in several psychiatric disorders including seasonal affective disorder (Postolache et al., 1999; Postolache et al., 2002), mood disorders (Pause et al., 2001; Gross-Isseroff et al., 1994; Lombion-Pouthier et al., 2006), anorexia nervosa (Kopala et al., 1995; Fedoroff et al., 1995; Roessner et al., 2005), panic disorder (Kopala and Good, 1996) and psychosis (Corcoran et al., 2005; Hudry et al., 2002; Moberg et al., 2003).

In this paper, the interest of olfaction testing as a potential cognitive marker of psychiatric disorders will be discussed with regard of recent published data, with a particular focus on depression and schizophrenia. Further, in order to assess the specificity of the olfactory markers dysfunction, we will also present research on olfaction alterations in dementia and neurodegenerative disorders that also include cognitive abnormalities. Before detailing these alterations, we will discuss the methods enabling the psychophysical assessment of olfactory perception. As some studies exploring olfactory deficits in psychiatric conditions are based on the assumption that such alterations may be related to the fact that brain areas involved in the processing of olfactory cues partially overlap with the structures having an altered functioning in these pathology, we will briefly detail the brain circuitry enabling the processing of odours. Then we will describe the alterations observed in schizophrenia, depression and neurodegenerative disease. We will first present data available on schizophrenia, as most studies exploring olfactory deficits in psychiatric conditions examined alterations in this pathology. We will then continue with the studies on olfactory deficits in depression and finish with the studies on neurodegenerative disorders.

\section{Psychophysical assessment the olfactory perception}

Olfactory function has historically been divided into two hierarchical and independent processes, the first being termed as "peripheral" (i.e., acuity or the ability to detect an odour) and the second one being called "central" (i.e., identification, discrimination, memory or the ability to name an odour) (Martzke et al., 1997). Deficits in acuity have been thought to reflect impairment in peripheral processes (defect in processing occurring at the level of the 
nasal epithelium, e.g. alterations in the olfactory receptors), while deficits in identification or memory might correspond to central impairment (defect in higher order brain processes, including alterations in cortical and limbic processing). This notion is based on studies that describe altered odour identification skills with preserved threshold ability in patients with lesions of the orbitofrontal cortex (OFC) or of the dorsomedial nucleus of the thalamus (Potter and Butters, 1980; Jones-Gotman and Zatorre, 1988).

To study the olfactory deficits in individuals with psychiatric disorders (schizophrenia and depression), three aspects of the olfactory function are mainly evaluated: the detection threshold, the odour identification and the odour quality discrimination. In order to obtain more information on the subject's olfactory perception and in order to avoid the influence of the different properties typical of each odorant on the subject's responses, several other odorant characteristics can be also assessed, including odour familiarity (odour recognition), odour intensity and odour pleasantness.

\section{- Detection threshold}

The detection threshold is the minimum concentration of a sensory stimulus needed to give rise to a sensation; at the threshold level, it can be that the sensation is not identified (AFNOR, 1992). According to Martzke et al. (1997), the evaluation of the detection threshold corresponds to a measure of the lowest concentration of a particular olfactory stimulus required to activate the olfactory receptors, thus resulting in the detection of that odour. The more used method for detection threshold evaluation in clinical studies is the single staircase method described by Doty et al. (1984; 1986). Phenyl-ethyl-alcohol (at serial dilutions) dissolved in mineral oil is frequently selected as a test odorant because it has a pleasant roselike smell and does not produce intranasal trigeminal sensations (Doty et al., 1978; ComettoMuniz and Cain, 1990). The subject has to detect the presence of the stimulus. For this, he is subjected to trials using different concentrations of the odorant stimulus. The principle of the method consists to increase the concentration of the stimulus following trials on which a subject fails to detect the stimulus and to decrease it following trials where correct detection occurs. Two bottles are presented to the subject, one containing the odorant solution whereas the other contains the solvent alone. The subject's task is to determine which of the two solutions evokes a stronger odour. If a correct response is made, the solution containing a smaller concentration of the odorant is presented along with a bottle containing only the solvent. The geometric mean of the last four of seven reversal points is used as the odour detection threshold estimate. This test is relatively reliable (test-retest reliability $\mathrm{r}=0.88$ ).

\section{- Odour identification}

In order to assess the olfactory identification ability of patients with neurological or psychiatric disorders, the University Pennsylvania Smell Identification Test (UPSIT, commercially available as the smell Identification Test, ${ }^{\mathrm{TM}}$ Sensonics, Inc., Haddon Heights, NJ) developed by Doty et al. (1984) is widely used (Postolache et al., 1999; Goudsmit et al., 2003; Corcoran et al., 2005). This test consists of four booklets, each containing 10 items. Each page contains one aroma compound, which is placed in fixed microcapsules at the bottom of the page. Next to each are four written identification alternatives. The subjects are required to identify, in a four alternative multiple choice format, forty odorants. This test is very reliable (test-retest reliability $r>0.95$ ) and sensitive to even subtle olfactory deficits present in a number of diseases, including Alzheimer's disease (Moberg et al., 1997), Parkinson's disease (Doty et al., 1995), schizophrenia (Kopala et al., 1997; Goudsmit et al., 2003) and depression (Postolache et al., 1999). 
Recently, a new olfactory test (ETOC, European Test of Olfactory Capabilities, conceived by EZUS, University Lyon II, France) has been proposed in order to study the olfactory perception (Thomas-Danguin et al., 2003). This test first assesss the olfactory sensitivity with two odours: 1-carvone (a menthol like odour) and tetrahydrothiophene (an additive odour for gas), using a forced choice procedure during 5 successive concentrations. Second, the test evaluates the detection and identification abilities with a set of 16 odours. For each of them, the subject identifies the bottle with an odour among four bottles (detection test) and then choose its correct label among a list of four names (identification test). This test was used with success to study the links between olfactory perception and several common illnesses appearing along ageing (Rouby and Thomas-Danguin, 2003) and in mood disorders (Lombion-Pouthier et al., 2006).

\section{- Odour quality discrimination}

The evaluation of the odour discrimination capacities is based on the measure of the individual's ability to differentiate the perception of the quality of one odour when compared to another one (simplest form) or to pick the odd odour out of a series of odorants, all of which are identical except one. Accurate performance on these tasks requires intact acuity but not identification (naming) of the odorant (Martzke et al., 1997). Olfactory discrimination can be assessed using a modification of the UPSIT after a method described by Doty et al. (1994). This test consists of one booklet containing 16 items. Each item has three microcapsules, two of which release identical odours and the third releasing a different odour. The subject's task is to choose the different odour of the triad. In order to avoid the influence of the odorant's hedonic aspect and intensity on the subject's response, these two properties are also evaluated. When compared with the other two olfactory functions cited above (detection odour threshold and odour identification) the qualitative discrimination ability is less used in order to study the olfactory deficits in psychiatric disorders.

\section{- Odour familiarity (odour recognition)}

Odour recognition is assessed by the familiarity level for the odorant. This characteristic is very important, because it can influence the subject's response on other criteria. For example, a positive relationship between familiarity and ratings of pleasantness is well established (Jellinek and Köster, 1983; Rabin and Cain, 1989). Odour familiarity can be assessed using a scale (Hudry et al., 2002). Some authors ask the subject whether the odour is familiar or unfamiliar, the answer possibilities being "yes" or "no" (Plailly et al., 2006).

\section{- Odour intensity}

The evaluation of the perceived odour intensity can be carried out in order to attain two principal objectives. The first one concerns the study the impact of the odour intensity on the subject's response (odour identification and odour quality discrimination). Indeed, it has been shown that a small difference in odour intensity between odorants can influence the subject's response. For this reason, all studied odorants must be presented to the subjects at isointensity (equal intensity). Further, it has been largely demonstrated that the different intensity levels of the same odorant can change the odour quality and, consequently, the subject's judgement (Gross-Isseroff and Lancet, 1988; Laing, et al., 2003). Studies in healthy people that have used intensity and pleasantness ratings of some odorants (amyl acetate and furfural), showed that pleasantness rating are highest at weak concentrations and decline progressively as odorant concentration increases (Henion, 1971; Moskowitz and Gerbers, 1974). The second objective concerns the study of the subject's discriminative power between the different intensity levels of the odorant. Indeed, this olfactory performance is very few studied in psychiatric disorders. 
The more used method to assess the perceived odour intensity in clinical studies is based on rating scales (Pause et al., 2001; Moberg et al., 2003).

\section{- Odour pleasantness}

A central feature of odour perception is its hedonic component. This view is supported by a number of studies investigating the dimensionality of olfactory evaluation, demonstrating that the greatest part of the variance between odours can be explained by their hedonic properties (Berglund et al., 1973; Pause et al., 2003). Odour pleasantness can be evaluated by using a scale (Hudry et al., 2002) or by measuring several emotional-related autonomic parameters such as electrodermal response, blood flow or heart rate (Alaoui-Ismaili et al., 1997). In the clinical field, hedonic scale is often used in order to study the odorant hedonic perception (Moberg et al., 2003; Hudry et al., 2002; Pause et al., 2001).

\section{Brain areas involved in olfaction}

In this paper, only process related to functioning of the main olfactory system in humans will be reviewed. Indeed, to our knowledge, no study investigated the alterations of processes related to a dysfunction of the accessory olfactory system in patients suffering from psychiatric conditions or dementia. In the main olfactory system, odour perception results first from the stimulation of olfactory receptors located on specialized neurons (olfactory receptor neurons) from the nasal olfactory epithelium. Axons from these primary olfactory neurons synapse in the olfactory bulb, information being then relayed further toward other parts of the brain. This first step corresponds to the treatment of olfactory information at the peripheral level. After bulb processing, information is processed in different brain areas, including the amygdala, the piriform cortex, the entorhinal cortex and the frontal cortex. Studies have reported that the representation of the intensity of odours is associated with activity in the piriform cortex (Rolls et al., 2003) and the amygdala (Anderson et al., 2003), while the orbitofrontal cortex has been found to be involved in odour identification, odour discrimination, judgement of the hedonic value of odours and odour memory (Zald and Pardo, 1997; Zald et al., 2002). For example, Levy et al. (1997) measured brain activation in response to olfactory stimuli (pyridine, menthone, amyl acetate) using functional Magnetic Resonance Imaging (fMRI). Activation occurred in the OFC, the entorhinal cortex as well as in the cingulate gyrus. Brain regions activated by odours considered pleasant or unpleasant did not differ. Fulbright et al. (1998) explored brain activation in response to pleasant and unpleasant odours, in 30 healthy subjects. Frontal activation occurred in response to pleasant and unpleasant odours in four areas (dorsal anterior cingulate area, prefrontal cortex, precentral gyrus, insula). Only pleasant odour resulted in activation of the left superior frontal gyrus as well as in activation in the right precentral gyrus and in the left anterior cingulate. Anderson et al. (2003), using an event-related fMRI, found amygdala activation associated with intensity of odours but not valence, while the activity in the OFC was associated with valence independently of intensity. Thus, the hedonic experience is a feature of orbitofrontal representations, which are modulated by changes in affective relevance. The hedonic experience is more dependent of the integrative functions of the prefrontal cortices (Anderson, 2003). Brain activation to olfactory stimuli was also explored with Positron Emission Tomography (PET) using either aversive or relatively pleasant olfactory stimuli. Aversive olfactory stimuli were associated with increased muscle tension, fear, disgust and repulsion and were related to the amygdala and to the left OFC (Zald and Pardo 1997). More pleasant stimuli were related to activity in the piriform cortex and the right OFC. Activation was almost uniformly present in OFC (Zatorre et al., 1992). Recently, Vaidya et al. (2007) exposed healthy subjects to pleasant and unpleasant olfactory stimuli to examine the association between positive emotionality and regional cerebral blood flow (rCBF) using PET. 
During the pleasant smell condition, positive emotionality (extraversion) was correlated with $\mathrm{rCBF}$ in the amygdala and in the occipital cortex. During the unpleasant smell condition, positive emotionality was correlated with $\mathrm{rCBF}$ in the occipital cortex and inferior temporal gyrus.

Interestingly, brain areas involved in the processing of olfaction are often altered in some psychiatric disease such as schizophrenia or major depression (see Table 1 for a summary of these data). This suggests that these pathologies may be accompanied by dysfunction of olfactory processing.

\section{Olfactory alterations in schizophrenia}

Because the olfactory system shares a common neural substrate with many of the cognitive and emotion processes that are abnormal in schizophrenia (Turetsky and Moberg, 2003), several authors have used olfactory measures to assess the functional integrity of the brain in patients with schizophrenia. An increasing number of studies have reported evidence that the processing of olfactory information is a cognitive function which is disturbed in patients with schizophrenia (Moberg et al., 1999; Rupp, 2003). These deficits have been found in most odour stimulation tasks (odour acuity, discrimination, recognition memory and identification tasks). Data presented bellow are summarized in Table 2.

\section{- Olfactory function at peripheral level}

Few studies have investigated olfactory acuity in this disease and findings are not always convergent. Several studies reported decreased olfactory sensitivity in schizophrenic patients (Isseroff et al., 1987, Serby et al., 1990, Sirota et al., 1999). However, most of the studies have found an intact sensitivity in schizophrenic patients (Kopala et al., 1989; Geddes et al., 1991; Kopala et al., 1993; Kohler et al. 2001) and even enhanced sensitivity (Bradley, 1984, Sirota et al., 1999). Impaired olfactory sensitivity in schizophrenic patients was attributed to long-term effects of neuroleptic treatment and parsimoniously to the anticholinergic properties of neuroleptic drugs which caused dryness of the olfactory mucosa (Sirota et al., 1999). Insofar as impaired identification has been found in schizophrenic patients in the absence of reduced sensitivity (Kopala et al. 1993; Kohler et al., 2001; Rupp et al., 2005), schizophrenic patients olfactory deficit has been described as an olfactory agnosia (Kopala and Clark, 1990).

\section{- Olfactory function at central level}

Most studies have demonstrated that patients with schizophrenia have deficits in odour identification (for example Kopala et al., 1989; Serby et al., 1990; Wu et al., 1993; Houlihan et al., 1994; Kopala et al., 1995; Kopala et al., 1995; Brewer et al., 1996; Moberg et al., 1997; Seidman et al., 1997; Stedman and Clair, 1998). Indeed, only one study did not find such a deficit (Mesholam et al., 1998). Odour identification deficits appear to be independent from smoking history (Seidman et al., 1991; Houlihan et al., 1994; Brewer et al., 1996; Brewer et al., 2001), cannabis use (Brewer et al., 2001), neuroleptic use (Seidman et al., 1991; Houlihan et al., 1994; Moberg et al., 1999; Brewer et al., 2001), clinical state, schizophrenia subtype, ethnicity or socioeconomic status (Coleman et al., 2002). These alterations have been found more common among male than female patients (Kopala et al., 1993) and more pronounced in post-menopausal than pre-menopausal women with schizophrenia (Kopala et al., 1995). In a meta-analytic review of literature on olfaction in schizophrenia, no significant influence of medication status or smoking on olfactory identification has been found (Moberg et al., 1999). These authors concluded that their findings support the hypothesis of a primary dysfunction of the olfactory system in schizophrenic patients. 
Deficits in odour discrimination or recognition have also been reported in schizophrenia (see Table 2), even if some studies failed to find such alteration.

Recent studies have assessed olfactory judgements in schizophrenic patients. Impairments in the edibility and familiarity judgments have been reported in schizophrenic patients, while intensity judgements were found intact (Hudry et al., 2002, Moberg et al., 2003, Plailly et al., 2006, Rupp et al., 2005). The findings concerning the hedonicity judgements are however discrepant with other findings. Indeed, most studies have found lower pleasantness ratings of odours (Crespo-Facorro et al., 2001, Hudry et al., 2002, Moberg et al., 2003, Plailly et al., 2006), while two studies reported controversially higher pleasantness ratings (Becker et al., 1993, Rupp et al., 2005). These divergent findings could be explained by the differences in symptoms among the groups and parsimoniously concerning anhedonia state (Becker et al., 1993). The disturbances of olfactory judgements have been associated with functional abnormalities in the temporo-limbic brain areas. Indeed, using PET, it as been shown that, when compared to controls, patients exhibit a deficit in the limbic/paralimbic and frontal activation associated with olfactory processing while doing olfactory judgement (e.g., insular cortex and parahippocampal gyrus) (Crespo-Facorro et al., 2001; Plailly et al., 2006).

A cross-sectional design suggested that olfactory ability is deteriorated according to the illness duration (Moberg et al., 1997). However, a follow-up assessment at 6 months indicated that the patient olfactory identification ability remained impaired over time (Brewer et al., 2001). These deficits have been found in neuroleptic naive schizophrenic patients (Kopala et al., 1993; Brewer et al., 2001) and neuroleptic withdrawn patients (Wu et al., 1993). Moreover, these alterations have been reported in early onset psychosis (Corcoran et al., 2005), schizotypic men (Park and Schoppe, 1997) and in relatives of patients with familial schizophrenia (Kopala et al., 1998; Kopala et al., 2001). These latter data suggest that the olfactory identification deficit would reflect a trait marker of psychosis.

Recent studies have linked this deficit with a clinical subgroup of patients. Indeed, the olfactory identification alterations have been correlated with deficit syndrome (Malaspina et al., 1994; Malaspina et al., 2002; Seckinger et al., 2004; Corcoran et al., 2005) and the key features of this syndrome, negative symptoms (Brewer et al., 1996; Brewer et al., 2001; Malaspina and Coleman, 2003; Corcoran et al., 2005), particularly social behavioural dysfunction (Brewer et al., 1996) and diminished social drive (Malaspina and Coleman, 2003). Intelligence Quotient has been found independent from the relationship between olfactory alterations and social drive (Malaspina and Coleman, 2003). Both deficit symptoms and olfactory deficit have been hypothesized to be a persistent trait of illness and to derive from structural and functional brain abnormalities (Seckinger et al., 2004).

Regarding the other symptoms of schizophrenia, smell deficits seem not associated with olfactory hallucinations (Kopala et al., 1994; Stedman and Clair, 1998), anhedonia (Stedman and Clair, 1998) and depressed mood (Brewer et al., 1996; Stedman and Clair, 1998; Malaspina and Coleman, 2003).

Several studies have explored the relationship between olfactory alterations and neuropsychological measures (Seidman et al., 1991; Seidman et al., 1997; Purdon, 1998; Stedman and Clair, 1998; Seckinger et al., 2004). Olfactory deficits could be a part of a general difficulty concerning sensory identification. This is however not the case. Indeed, schizophrenic patients have been found to perform in the normal range on colour Identification, a sensory task which is as complex as odour identification tasks (Kopala et al., 
1995). Attention and executive functions are cognitive functions typically associated with schizophrenia and with dorsolateral frontal cortex function. However, olfaction identification deficits have not been found to be significantly associated with attention and executive functions as measured by the Wisconsin Card Sorting Test (Seidman et al., 1991), the Continuous Performance Task (Seidman et al., 1991; Seidman et al., 1997), the Letter Cancellation Task (Stedman and Clair, 1998) or the Stroop Colour-Word Test (Purdon, 1998). Two studies concluded however that odour identification ability might be associated with the function of the dorsolateral prefrontal cortex (Brewer et al., 1996; Saoud et al., 1998).

In a sample of schizophrenic patients (Stedman and Clair, 1998), WAIS-R Information score (Wechsler Adult Intelligence Scale-Revised) that estimates Intelligence Quotient and Wisconsin Card Sort Test Failure to Maintain Set score (WCST-FMS) that may imply orbitofrontal function were the only significant neuropsychological predictors of the odour identification tests, accounting for $41 \%$ of the variance. Moreover, a moderate correlation has been found in several studies between olfaction identification deficits and verbal ability (Seidman et al., 1991; Seidman et al., 1997; Seckinger et al., 2004). Finally, in schizophrenic patients with deficit syndrome, these alterations have been associated to deficits in complex visual-motor organizational functions (i.e., Block Design and Object Assembly) that are thought to be mediated by the parietal area (Seckinger et al., 2004).

As previously mentioned, plfactory pathways have a complex distribution in brain overlaping with several brain regions suggested to be implicated in functional or structural abnormalities of schizophrenia. Thus, impairments in olfactory information can result of a disruption anywhere along the complex olfactory pathways (Malaspina et al., 1998). Analysis of olfactory epitheliums removed from schizophrenic patients has reported inconstant outcomes. While some authors have found histochemical and morphological abnormalities (Feron et al., 1999; Arnold et al., 2001), others have found an intact olfactory epithelium (Smutzer et al., 1998). Patients with schizophrenia have been found to exhibit a reduced volume of the olfactory bulb, but no correlation between the olfactory bulb volume and odour threshold sensitivity was observed (Turetsky et al,. 2000). Finally, in a study using olfactory eventrelated potential responses in schizophrenic patients, abnormalities in the amplitudes of the $\mathrm{N} 1$ and P2 components of the olfactory evoked potential, and delayed latency of the P2 but not delayed latency of the N1 have been reported (Turetsky et al., 2003). Insofar as the amplitude $\mathrm{N} 1$ is associated to the primary auditory cortex, the authors interpreted the fact that the N1 latency was normal as evidence that basic signal transmission from peripheral receptor neurons through the olfactory bulb to the primary sensory cortex is not disturbed in patients, despite the fact that abnormalities may exist in the pathway. Thus, olfactory deficits observed in schizophrenia are supposed to have a central origin.

As indicated previously, in normal subjects, the ability to identify odours has been linked to prefrontal, particularly OFC while acuity has been attributed to medial-temporal regions (Brewer et al., 2001). To date, a small number of functional imaging studies have explored olfactory deficits in schizophrenic patients. In a PET study, Clark et al. (1991) reported that patients with schizophrenia and an olfactory agnosia had a lower right basal ganglia and thalamic metabolism than the normosmic patients with schizophrenia, suggesting dysfunction in subcortical brain regions associated with olfaction. Using single photon emission computed tomography (SPECT) Malaspina et al. (1998) have reported right frontal and medial temporal area hypometabolism in schizophrenic patients while performing odour identification task. In a PET study, Bertollo et al. (1996) found hypometabolism in the right OFC, theorized to receive uncrossed inputs from the olfactory bulbs. In another PET study, Crespo-Facorro et al. 
(2001) found that schizophrenic patients failed to activate limbic and paralimbic regions during the experience of an unpleasant odour. Recently, Schneider et al. (2007) used a fMRI combined to negative odour stimuli and measured an hypofunctional activity in regions of the right frontal and temporal cortex in schizophrenic patients. Finally, preliminary neuroimaging studies in patients with schizophrenia tend to support greater association of olfactory deficits with right hemisphere and heteromodal association areas.

\section{Olfactory alterations in depression}

Olfactory deficits have been investigated in depression for three main reasons: a) the olfactory processing at the brain level recruits areas whose functioning is altered in depression (see Table 1), such as the OFC (Drevets, 2007); b) bilateral olfactory bulbectomy in rodents induces changes in behaviour, as well as in the endocrine, immune and neurotransmitter systems, that are isomorphic to many of those seen in patients with major depression (Leonard and Song, 2005). These alterations are reversed by antidepressants, suggesting that part of the abnormalities seen in depression could be related to abnormalities of the neural olfaction pathways and of its projections; c) stress, which is one of the factor precipitating a depressive episode in vulnerable subjects, induces behaviour similar to some symptoms of depression as well as decreased cell proliferation or neurogenesis, both in the hippocampus and in the olfactive bulbs (Mineur et al., 2007). Thus, we will review the olfactory alterations seen in depressed subjects in an extensive way. These data are synthesized in Table 2.

\section{Olfactory function at peripheral level}

Most of the studies showing a difference of olfactory acuity between patients and controls revealed a reduced olfactory sensitivity in depressed patients (Serby et al., 1990; Pause et al., 2001; Lombion-Pouthier et al., 2006). Recently, Pollatos and colleagues (2007) studied the olfactory sensitivity in healthy subjects with depressive symptoms and observed a significant negative correlation between olfactory sensitivity and depressive symptoms. Pause et al. (2001) compared the olfactory sensitivity before and after drug treatment and showed significant correlations between self-descriptions of depression and olfactory sensitivity only during the first session, before the treatment. After subjective recovery from the depressive mood, following psychiatric treatment, patients still showed a slightly lower olfactory sensitivity; however, neither the group (patients and controls) differences nor the correlations reached the significance level. Unlike the results described previously, different authors found greater rather than weaker odour detection ability in patients with major depression than in healthy controls (Gross-Isseroff et al., 1994; Postolache et al., 2002). Precisely, the researchers reported that depressed patients in remission after 6 weeks of antidepressant treatment exhibit higher olfactory acuity than healthy subjects. Thus, it is possible that antidepressant treatment per se may be responsible for the changes in olfactory sensitivity. Therefore, it is not possible to decide whether the increased olfactory sensitivity is a state or a trait marker of the depression. In order to answer this question, it would be of valuable interest to perform two additional measurements: one before starting the antidepressant therapy and one some months after stable remission. All the studies presented above suggest that reduced olfactory sensitivity may be a marker of depression, which can be affected by medications. To our knowledge, there is also one study, which did not find a difference between unmedicated patients and controls (Postolache et al., 1999). These last authors explained this discrepancy by a difference in odours presentation (unilateral or bilateral).

\section{Olfactory function at central level}

In order to study the olfactory function at central level, odour identification measurements have often been carried out. Only one study demonstrated decreased olfactory identification in 
patients with depression (Serby et al., 1990). Indeed, most of the studies reported intact odour identification in depressed patients (Amsterdam et al., 1987; Solomon et al., 1998; Postolache et al., 1999; Lombion-Pouthier et al., 2006). This is confirmed by Solomon et al. (1998), who compared the olfactory perception between groups of patients with Alzheimer's disease and major depression and reported an olfactory alteration only for patients with Alzheimer's disease. Authors concluded that olfactory assessment may by a useful adjunctive screening measure enabling to differentiate Alzheimer's disease from depression in elderly patients.

Among the studies cited previously, few explored simultaneously the other aspects that are usually assigned to olfactory perception (sensitivity, intensity, pleasantness, identification). With regard to perceived odour intensity, no significant difference was found between depressed patients and healthy subjects (Lombion-Pouthier et al., 2006; Pause et al., 2001). The studies of Lombion-Pouthier et al. (2006) and Pause et al. (2001) were the sole ones that evaluated the hedonic ratings for several odours. Selecting only pleasant odorants, the first study showed that depressed patients over-evaluated the pleasantness. The authors found these ratings surprising as the depressed subjects usually experienced negatively emotional cues and as explanation suggested a functional consequence of the brain processes underlying depressive states (Lombion-Pouthier et al., 2006). These alterations could be related to dysfunctions of the OFC, a brain area associated to the hedonic evaluation of odours (Savic, 2001). Indeed, its activity seems also increased in depressive states (Drevets, 1998; Pause et al., 2003). The second study, carried out by Pause et al. (2001), observed a trend to differ for the valence ratings only for one out of ten studied odours: citral, which was perceived as more pleasant by the depressive and not by the control subjects. The authors explained this observation by the relaxing properties of the lemon-like odour. Indeed, according to Lawless (1991) lemon-like odours were shown to have a relaxing effect in healthy subjects. Thus, depressive patients may respond more sensitively to odours with relaxing properties.

Only few studies explored brain processing of olfactory information in depressed patients. Indeed, most of these studies have been conducted in healthy volunteers as well as in patients suffering from schizophrenia or neurodegenerative diseases. Depression is associated with a cognitive bias for emotionally negative stimuli. In neuroimaging studies, depression has been repeatedly characterized with abnormal activation in various brain regions including the amygdala, the anterior cingulate cortex, the OFC and the prefrontal cortex (Drevets, 1998) (see Table 1 for a review). The activity in the dorsal prefrontal cortex has been linked to impaired cognitive processes necessary for executive control. The OFC plays a special role in behaviours produced by rewards and punishers, which happen to encompass in particular emotional and motivational behaviours (Rolls, 2004). It is generally believed that the OFC integrates sensory information and internal information mainly arriving from the amygdala and the thalamus to assign emotional significance to certain events. Brain imaging studies reliably report elevated amygdala activity in depressed subjects (Schneider et al., 1996). It is suggested that the processing of basic olfactory properties is ruled by the amygdala (Savic et al., 2000), which may play a crucial role in the perceptual encoding of the emotional significance of information whereas the OFC uses this information for executive control. Studies on the role of the OFC and the amygdala in emotion parallel the studies on these brain structures in olfaction. Both structures are known to be functionally impaired in depression (Pause et al., 2003).

There was no evidence of a significant association between negative emotionality (neuroticism) and rCBF in the left or right amygdala to the pleasant or unpleasant smell. The authors recommend exploring brain activation in response to positive as well as negative 
stimuli in subjects with depression, as depression may be associated with decreased activation in regions subserving positive evaluation of stimuli, including the amygdala.

Drevets (2007) suggested that orbitofrontal regions are functionally distinct with respect to mood regulation. The posterior lateral and medial OFC function may be impaired in individuals who develop primary mood disorders. In contrast, metabolic activity in the anteromedial OFC was positively correlated with depression severity and inversely correlated with the antidepressant pharmacotherapy in major depressive disorder and bipolar disorder. The author concluded that both types of areas may participate in the physiopathology of depression, which results from dysfunction within a neural network involving the OFC, medial prefrontal cortex, amygdala and anatomically related areas (temporal lobe, striatum, thalamus and brainstem).

Lombion-Pouthier et al. (2006) suggested that an abnormal limbic functionality in depressed patients could be associated with an altered olfactory perception. The amygdala and the piriform cortex were hypothesized to be responsible for a reduced olfactory sensitivity as well as for alterations in the processing of emotional stimuli. Pause et al. (2003) demonstrated that, even with a reduction in the ability to encode basic olfactory information, the odour identification abilities and subjective odour evaluations (intensity and valence) in depressive patients were similar to the ones of control subjects. The rCBF differences between depressed patients and controls have been evidenced in brain regions involved in appetitive conditioning, such as the amygdala, the ventral striatum, the anterior cingulate cortex and the prefrontal and lateral OFC (Drevets, 2001). An fMRI study of appetitive conditioning showed dysfunctional learning in both appetitive and aversive learning conditions associated with a pattern of dysfunction of amygdala, lateral OFC, striatum (caudate nucleus) and anterior cingulated cortex in depression (Martin-Soelch, 2007).

Further studies in cerebral imaging are required in order to define the brain structures specifically implicated in the olfaction and in its emotional correlates during and after episodes of depression. Marciani et al. (2006) proposed recently an improved fMRI method for studying the cortical representation of stimuli containing flavor using a pseudo-natural delivery stimulation protocol. Several brain areas were found to be activated, including the dorsolateral prefrontal cortex, anterior cingulated cortex, hippocampus and medial orbitofrontal cortex.

In summary, most studies on olfactory perception in depression showed that depressed patients principally exhibit a deficit in the hedonic aspects of this perception, even if, in some case, alterations in sensitivity or identification are also found. Given that many studies on depression demonstrated abnormal activation in various brain regions including the amygdala, the anterior cingulate and the prefrontal cortex (Drevets et al., 1992; Siegle et al., 2002; 2007; Deckersbach et al., 2006a; 2006b; Wagner, 2006), it has been suggested that a deviant limbic functionality in depressed subjects could be associated with the observed altered olfactory perception (Pause et al. 2001; Lombion-Pouthier et al., 2006). Pause et al. (2001; 2003) hypothesized that functional deviations within brain regions involved in the early perceptual processing of odours, such as the amygdala and piriform cortex, could be responsible for the reduced olfactory sensitivity, as well as for alterations in the processing of emotional stimuli in depressed patients.

Several new perspectives are offered following the results obtained on olfactory perception in depression. First, it cannot be excluded that the impairments of olfactory perception 
themselves generate some symptoms of depression, related to the influence of odour perception on emotions, mood or behaviour. The question is whether the affected olfaction in healthy subjects could generate a depression. There is evidence suggesting that emotionrelated personality traits have an impact on olfactory function in healthy subjects. Chen and Dalton (2005) studied the effect of emotion and personality on olfactory perception and demonstrated that neurotic and anxious individuals react faster to emotionally valenced odours then to neutral odours. In this context, a recent study carried out using a large general population sample was able to show a strong correlation between neuroticism and symptoms of depression as assessed by the Beck Depression Inventory (Jylha and Isometsa, 2006). Taking both of these studies together and bearing in mind that Pause et al. (2001) reported a positive correlation between lowered olfactory sensitivity and elevated depression scores as measured by the Beck Depression Inventory in patients suffering from major depression, it can be conjectured that depressive symptoms might be related to a reduced olfactory sensitivity as well. This hypothesis was supported by Pollatos et al. (2007) who observed a significant negative correlation between olfactory sensitivity and depressive symptoms. Second, it is interesting to study the possibility that anhedonia can be expressed also at the olfactory level. This has already been suggested using a gustatory stimulus in depression and schizophrenia (Berlin et al., 1998). The authors showed that the hedonic responses to sucrose solutions and sweet taste perception threshold may be used as complementary evaluation to quantify anhedonia.

\section{Olfaction in dementia and other cognitive disorders}

A meta-analysis of 43 studies on olfaction in Alzheimer's Disease (AD) and Parkinson's Disease shows that both identification, recognition and detection threshold are significantly altered in neurodegenerative disorders compared to normal aged controls (Mesholam et al., 1998). Comparing 92 demented patients with 94 control subjects, Mc Shane et al. have shown that olfactory performances discriminate patients with Senile Dementia of Lewy body type from AD patients (McShane et al., 2001). More recent data suggest that the level of memory impairment in $\mathrm{AD}$ patients does not seem to affect the performances at the olfactory testing (Kjelvik et al., 2007). Nevertheless, olfactory performances in elderly subjects seem to be correlated mainly to language and memory performances, in a lesser extend to attention, visuospatial and executive functions. These findings suggest that olfaction performances are associated with other measures of temporo-limbic functioning (Westerweldt et al., 2005). These results are summarized in Table 2.

\section{Factors, which can influence the olfactory perception}

The discrepant results observed in a few studies on olfactory sensitivity in schizophrenia and depression or on identification task in depression can be explained by methodological differences, such as the choice of the evaluation method (methods for odour identification evaluation: UPSIT, ETOC, PST: Pocket Smell test), differences in diagnostic subgroups, differences in odours presentation (unilateral or bilateral), differences in studied odours and differences in subjects. For example, with regard to subject characteristics, age is known to have a strong influence on the results of psychophysical tests of olfaction (Doty, 1989). There is a progressive decline in the ability to detect and identify odours by subjects over 60 years of age. It has also been demonstrated that gender differences in olfactory abilities exist all along the pathway of perception from smelling behaviour to the complex processes of cognitive treatment (Millot and Brand, 2000; Brand and Millot, 2001). In general, women tend to score higher than men on tests of odour identification, discrimination and memory. Concerning the choice of the different olfactory stimuli, four main odours characteristics could influence the subject's perception: its trigeminal function (Doty et al., 1978), its 
intensity (Brand et al., 2001), its hedonic valence (Brand et al., 2001; Royet et al., 2003; Pause et al., 2003) and its intensity. Several odorants stimulate both the olfactory nerve and the trigeminal nerve. Moreover, odorants having no impact on the trigeminal system at low concentrations may stimulate the trigeminal system when using higher concentrations. It is well know that the perception of smell is dominated by a hedonic odour valence. As previously highlighted, neuroanatomy suggests a high level of functional connectivity between the olfactory and limbic systems. A comparative study using fMRI showed that depending on the stimulus, the activated cortical areas can differ (Fulbright et al., 1998). With the clementine odour, certain regions were activated asymmetrically (for example Brodmann's area 32 was activated preferentially in the left hemisphere and area 6 preferentially in the right hemisphere) whereas the unpleasantness of isovaleric acid did not produce any asymmetry. Davidson (1992) explained these hemispheric differences according to the hedonic valence of odours. As for the odour intensity, it has been demonstrated that the different intensity levels of the same odorant can change the odour quality and, consequently, the subject's judgement (Gross-Isseroff and Lancet, 1988; Laing, et al., 2003).

\section{General discussion}

Taken together, these data indicate that olfactory abnormalities might be a marker of psychiatric conditions, with a specific pattern for each disease. Indeed, no reliable change in odour sensitivity is seen in schizophrenic patients, indicating that these patients show no deficit in the peripheral aspects of odour perception. Thus, no abnormality related to purely sensorial deficits is seen in this pathology. This is not the case of depression, dementia or neurodegenerative disease, as these patients exhibit such an alteration in some case. This indicates that the deficits seen in the psychiatric patients have a specific pattern.

Odour identification is altered in schizophrenic patients. This deficit has been associated to alterations in processing occurring at the right frontal and medial temporal levels, where hypometabolism has been found in the schizophrenic patients while undertaking the identification task. It would be interesting to investigate whether similar alterations are found in disease characterized by alteration in right frontal and medial temporal areas.

Odour intensity judgement was intact in depressive and schizophrenic patients. Changes in odour perception are also found in dementia and in some neurodegenerative disease, but in this case alterations concern all aspects of the sensorial experience (identification and recognition) and they are thus a-specific.

Taken together, this review shows that each of these disorders is characterized by a specific pattern, which can then be considered as a signature of each condition. When present, these alterations concern the sensorial treatment in depression dementia and neurodegenerative disease. The deficits concerned also the cognitive aspect of the olfactory experience (identification) and the affective aspects. These alterations should thus be considered in relationship with the clinical feature of these disorders that include alterations in sensorial gating (schizophrenia) or in the ability to experience pleasurable experience (the anhedonia seen in depression but also in schizophrenia). They may also be related to precise neurobiological alterations, even if further studies are needed to document this point. Further, additional studies are necessary in order to investigate whether such signatures (deficit in odour sensitivity, deficit in identification, deficits in the affective processing related to olfaction) are specific of these conditions or whether they can also be found in other disease, related or not to psychiatric conditions. 


\section{REFERENCES}

Abi Dargham, A., Gandelman, M.S., DeErausquin, G.A., Zea-Ponce, Y., Zoghbi, S.S., Baldwin, R.M., Laruelle, M., Charney, D.S., Hoffer, P.B., Neumeyer, J.L., Innis, R.B., 1996. SPECT imaging of dopamine transporters in human brain with iodine-123fluoroalkyl analogs of beta-CIT. Journal of Nuclear Medicine 37, 1129-1133.

AFNOR, 1992. Analyse sensorielle: Vocabulaire. NF ISO 5492. In: AFNOR (eds.), La Défense, Paris.

Alaoui-Ismaili, O., Vernet-Maury, E., Dittmar, A., Delhomme, G., Chanel, J., 1997. Odor hedonics: connection with emotional response estimated by autonomic parameters. Chemical Senses 22, 237-248.

Amsterdam, J.D., Settle, R.G., Doty, R.L., Abelman, E., Winokur, A., 1987. Taste and smell perception in depression. Biological Psychiatry 22, 1481-1485.

Anderson, A.K., Christoff, K., Stappen, I., Panitz, D., Ghahremani, D.G., Glover, G., Gabrieli, J.D., Sobel, N., 2003. Dissociated neural representations of intensity and valence in human olfaction. Nature Neuroscience 6, 196-202.

Arnold, S.E., Trojanowski, J.Q., 1996. Recent advances in defining the neuropathology of schizophrenia. Acta Neuropathologica 92, 217-231.

Arnold, S.E., Han, L.Y., Moberg, P. J., Turetsky, B. I., Gur, R. E., Trojanowski, J. Q.,Hahn, C.G., 2001. Dysregulation of olfactory receptor neuron lineage in schizophrenia. Archives of General Psychiatry 58, 829-835.

Becker, E., Hummel, T., Piel, E., Pauli, E., Kobal, G., Hautzinger, M. (1993). Olfactory event-related potentials in psychosis-prone subjects. Int J Psychophysiol 15, 51-8.

Berglund, B., Berglund, U., Engen, T., Ekman, G., 1973. Multidimensional analysis of twenty-one odors. Scandinavian Journal of Psychology 14, 131-137.

Berlin, I., Givry-Steiner, L., Lecrubier Y., Puech, A.J., 1998. Measures of anhedonia and hedonic responses to sucrose in depressive and schizophrenic patients in comparison with healthy subjects. European Psychiatry 13, 303-309.

Bertollo, D.N.,. Cowen, M.A., Levy, A.V., 1996. Hypometabolism in olfactory cortical projection areas of male patients with schizophrenia: an initial positron emission tomography study. Psychiatry Research 60, 113-116.

Bradley, E. A. (1984). Olfactory acuity to a pheromonal substance and psychotic illness. Biol Psychiatry 19, 899-905.

Brand, G., Millot, J.L., 2001. Sex differences in human olfaction: between evidence and enigma. Quarterly Journal of Experimental Psychology 54B, 259-270.

Brand, G., Millot, J.L., Henquell, D., 2001. Complexity of olfactory lateralization processes revealed by functional imaging: a review. Neuroscience \& Biobehavioral Reviews 25, $159-166$

Brewer, W.J., Edwards, J., Anderson, V., Robinson, T., Pantelis, C., 1996. Neuropsychological, olfactory, and hygiene deficits in men with negative symptom schizophrenia. Biological Psychiatry 40, 1021-1031.

Brewer, W.J., Pantelis, C., Anderson, V., Velakoulis, D., Singh, B., Copolov, D.L., McGorry, P.D., 2001. Stability of olfactory identification deficits in neuroleptic-naive patients with first-episode psychosis. American Journal of Psychiatry 158, 107-115.

Campbell, S., MacQueen, G., 2006. An update on regional brain volume differences associated with mood disorders. Current Opinion in Psychiatry 19, 25-33.

Chamberlain, S.R., Sahakian, B.J., 2006. The neuropsychology of mood disorders. Current Psychiatry Reports 8, 458-453.

Chen, D., Dalton, P., 2005. The effect of emotion and personality on olfactory perception, Chemical Senses 30, 345-351. 
Clark, C., Kopala, L., Hurwitz, T., Li, D., 1991. Regional metabolism in microsmic patients with schizophrenia. Canadian Journal of Psychiatry 36, 645-650.

Coleman, E.R. Goetz, R.R., Leitman, D., Yale, S., Stanford, A., Gorman, J.M., Malaspina, D., 2002. Odor identification impairments in schizophrenia: relationships with demographic measures, clinical variables, and diagnostic subtypes. CNS Spectrums 7, 43-48.

Cometto-Muniz, J.E., Cain, W.S., 1990. Thresholds for odor and nasal pungency. Physiology \& Behavior 48, 719-725.

Corcoran, C., Whitaker, A., Coleman, E., Fried, J., Feldman, J., Goudsmit, N., Malaspina, D., 2005. Olfactory deficits, cognition and negative symptoms in early onset psychosis. Schizophrenia Research 80, 283-293.

Crespo-Facorro, B., Paradiso S., Andreasen, N.C., O'Leary, D.S., Watkins, G.L., Ponto, L.L., Hichwa, R.D., 2001. Neural mechanisms of anhedonia in schizophrenia: a PET study of response to unpleasant and pleasant odors. Journal of American Medical Association 286, 427-435.

Davidson, R.J., 1992. Emotion and affective style: hemispheric substrates. Psychological Science 3, 39-42.

Deckersbach, T., Dougherty D.D., Rauch, S.L., 2006a. Functional imaging of mood and anxiety disorders. Journal of Neuroimaging 16, 1-10.

Deckersbach, T., Miller, K.K., Klibanski, A., Fischman, A., Dougherty, D.D., Blais, M.A., Herzog D.B., Rauch, S.L., 2006b. Regional cerebral brain metabolism correlates of neuroticism and extraversion. Depression and Anxiety 23, 133-138.

Dickinson, D., Iannone, V.N., Wilk, C.M., Gold, M., 2004. General and specific cognitive deficits in schizophrenia. Biological Psychiatry 55, 826-833.

Doty, R.L., 1989. Influence of age and age-related diseases on olfactory function. Annals of the New York Academy of Sciences 561, 76-86.

Doty, R.L., Brugger, W.E., Jurs, P.C., Orndorff, M.A., Snyder, P.J, Lowry, L.D., 1978. Intranasal trigeminal stimulation from odorous volatiles: Psychometric responses from anosmic and normal humans. Physiology \& Behavior 20, 175-185.

Doty, R.L., Shaman, P., Dann., M., 1984. Development of the university of pennsylvania smell identification test: A standardized microencapsulated test of olfactory function. Physiology \& Behavior 32, 489-502.

Doty, R.L., Gregor T.P., Settle R.G., 1986. Influence of intertrial interval and sniff-bottle volume on phenyl ethyl alcohol odor detection thresholds. Chemical Senses 11, 259-264.

Doty, R.L., Smith, R., McKeown, D., Raj J., 1994. Test of human olfactory function: Principal component analysis suggests that most measure a common source of variance. Perception \& Psychophysics 56, 701-707.

Doty, R.L., Bromley, S.M., Stern, M.B., 1995. Olfactory Testing as an Aid in the Diagnosis of Parkinson's Disease: Development of Optimal Discrimination Criteria. Neurodegeneration 4, 93-97.

Drevets, W.C., 1998. Functional neuroimaging studies of depression: The anatomy of melancholia. Annual Reviews in Medicine 49, 341-361.

Drevets, W.C., 2001. Neuroimaging and neuropathological studies of depression: implications for the cognitive-emotional features of mood disorders. Current Opinion in Neurobiology 11, 240-249.

Drevets, W.C., 2007. Orbitofrontal cortex function and structure in depression. Annals of the New York Academy of Sciences, in press. 
Drevets, W.C., Videen, T.O., Price, J.L., Preskorn, S.H., Carmichael, S.T., Raichle, M.E., 1992. A functional anatomical study of unipolar depression. Journal of Neuroscience 12, 3628-3641.

Dunn, T. P., Weller, M. P. (1989). Olfaction in schizophrenia. Percept Mot Skills 69, 833-4.

Fedoroff, I.C., Stoner, S.A., Andersen, A.E., Doty, R.L., Rolls, B.J., 1995. Olfactory dysfunction in anorexia and bulimia nervosa. International Journal of Eating Disorders $18,71-77$.

Feron, F., Perry, C., Hirning, M.H., McGrath J., Mackay-Sim, A., 1999. Altered adhesion, proliferation and death in neural cultures from adults with schizophrenia. Schizophrenia Research 40, 211-218.

Fulbright, R.K., Skudlarski, P., Lacadie, C.M., Warrenburg, S., Bowers, A.A., Gore J.C., Wexler, B.E., 1998. Functional MR imaging of regional brain responses to pleasant and unpleasant odors. American Journal of Neuroradiology 19, 1721-1726.

Geddes, J., Huws, R., Pratt, P., 1991. Olfactory acuity in the positive and negative syndromes of schizophrenia. Biological Psychiatry 29, 774-778.

Good, K. P., Martzke, J. S., Honer, W. G., Kopala, L. C. (1998). Left nostril olfactory identification impairment in a subgroup of male patients with schizophrenia. Schizophr Res 33, 35-43.

Goudsmit, N., Coleman, E., Seckinger, R.A., Wolitzky, R., Stanford, A.D., Corcoran, C., Goetz R.R., Malaspina, D., 2003. A brief smell identification test discriminates between deficit and non-deficit schizophrenia. Psychiatry Research 120, 155-164.

Gross-Isseroff, R., Lancet, D., 1988. Concentration-dependent changes of perceived odor quality. Chemical Senses 13, 191-204.

Gross-Isseroff, R., Luca-Haimovici, K., Sasson, Y., Kindler, S., Kotler M., Zohar, J., 1994. Olfactory sensitivity in major depressive disorder and obsessive compulsive disorder. Biological Psychiatry 35, 798-802.

Gur, R.E., Keshavan, M.S., Lawrie, S.M., 2007. Deconstructing psychosis with human brain imaging. Schizophrenia Bulletin 33, 921-931.

Hajek, T., Carrey, N., Alda, M., 2005. Neuroanatomical abnormalities as risk factors for bipolar disorder. Bipolar Disorders 7, 393-403.

Henion, K.E., 1971. Odor pleasantness and intensity: a single dimension? Journal of Experimental Psychology 90, 275-279.

Hindmarch, I., 2002. Beyond the monoamine hypothesis: mechanisms, molecules and methods. European Psychiatry 17, 294-299.

Houlihan, D.J., Flaum, M., Arnold, S.E., Keshavan, M., Alliger, R., 1994. Further evidence for olfactory identification deficits in schizophrenia. Schizophrenia Research 12, 179182.

Hudry, J., Saoud, M., Amato, T., Daléry, J., Royet, J.P., 2002. Ratings of Different Olfactory Judgements in Schizophrenia. Chemical Senses 27, 407-416.

Hurwitz, T., Kopala, L., Clark, C., Jones, B. (1988). Olfactory deficits in schizophrenia. Biol Psychiatry 23, 123-8.

Isseroff, R., Stoler, M., Ophir, D., Lancet, D., Sirota, P., 1987. Olfactory sensitivity to androstenone in schizophrenic patients. Biological Psychiatry 22, 922-925.

Jellinek, L., Köster, E.P., 1983. Perceived fragrance complexity and its relationship to familiaity and pleasantness II. Journal of the Society of Cosmetic Chemists 34, 83-97.

Jiang, W., Zhang, Y., Xiao, L., Van Cleemput, J., Ji, S.P., Bai, G., Zhang, X., 2005. Cannabinoids promote embryonic and adult hippocampus neurogenesis and produce 
anxiolytic- and antidepressant-like effects. Journal of Clinical Investigation 115, 31043116.

Jylha, P., Isometsa, E., 2006. The relationship of neuroticism and extraversion to symptoms of anxiety and depression in the general population. Depression and Anxiety 23, 281-285.

Jones-Gotman, M., Zatorre, R.J., 1988. Olfactory identification deficits in patients with focal cerebral excision. Neuropsychologia 26, 387-400.

Kjelvik, G., Sando, S.B., Aasly, J., Engedal, K.A., White, L.R., 2007. Use of the Brief Smell Identification Test for olfactory deficit in a norvegian population with Alzheimer's disease. International Journal of Geriatric Psychiatry 22, 1020-1024.

Kohler, C.G., Moberg, P.J., Gur, R.E., O'Connor, M.J., Sperling, M.R., Doty, R.L., 2001. Olfactory dysfunction in schizophrenia and temporal lobe epilepsy. Neuropsychiatry, Neuropsychology, and Behavioral Neurology 14, 83-88.

Kopala, L., Clark, C., 1990. Implications of olfactory agnosia for understanding sex differences in schizophrenia. Schizophrenia Bulletin 16, 255-261.

Kopala, L.C., Good, K.P., 1996. Olfactory identification ability in patients with panic disorder. Journal of Psychiatry \& Neuroscience 21, 340-342.

Kopala, L., Clark, C., Hurwitz, T.A., 1989. Sex differences in olfactory function in schizophrenia. American Journal of Psychiatry 146, 1320-1322.

Kopala, L., Good, K., Martzke, J., Hurwitz, T., 1995. Olfactory deficits in schizophrenia are not a function of task complexity. Schizophrenia Research 17, 195-199.

Kopala, L.C., Clark, C., Hurwitz, T., 1993. Olfactory deficits in neuroleptic naive patients with schizophrenia. Schizophrenia Research 8, 245-250.

Kopala, L.C., Good, K.P., Honer, W.G., 1994. Olfactory hallucinations and olfactory identification ability in patients with schizophrenia and other psychiatric disorders. Schizophrenia Research 12, 205-211.

Kopala, L.C., Good, K., Honer, W.G., 1995. Olfactory identification ability in pre- and postmenopausal women with schizophrenia. Biological Psychiatry 38, 57-63.

Kopala, L.C., Good, K., Goldner, E.M., Birmingham, C.L., 1995. Olfactory identification ability in anorexia nervosa. Journal of Psychiatry \& Neuroscience 20, 283-286.

Kopala, L.C., Good, K.P., Lopeter, W., Koczapski, A., Honer, W.G., 1997. Impaired olfactory identification ability and acuity in patients with schizophrenia and severe polydipsia: evidence for a degenerative process? Schizophrenia Research 24, 111-111.

Kopala, L.C., Good, K.P., Torrey, E.F., Honer, W.G., 1998. Olfactory function in monozygotic twins discordant for schizophrenia. American Journal of Psychiatry 155, 134-136.

Kopala, L.C., Good, K.P., Morrison, K., Bassett, A.S., Alda, M., Honer, W.G., 2001. Impaired olfactory identification in relatives of patients with familial schizophrenia. American Journal of Psychiatry 158, 1286-1290.

Kuyken, W., Dalgleish, T., Holden, L., 2007. Advances in cognitive-behavioural therapy for unipolar depression. Canadian Journal of Psychiatry 52, 5-13.

Laing, D.G., Legha, P.K., Jinks, A.L., Hutchinson, I., 2003. Relationship between molecular structure, concentration and odor qualities of oxygenated aliphatic molecules. Chemical Senses 28, 57-69.

Lawless, H., 1991. Effects of odors on mood and behavior: aromatherapy and related effects. In: Lang, D.G., Doty R.L., Breipohl, W. (Eds.), The Human Sense of Smell. SpringerVerlag, Berlin, pp. 361-386.

Levy, L.M., Henkin, R.I., Hutter, A., Lin, C.S., Martins, D., Schellinger, D., 1997. Functional MRI of human olfaction. Journal of Computer Assisted Tomography 21, 849-856. 
Lombion-Pouthier, S., Vandel, P., Nezelof, S., Haffen, E., Millot, J.L., 2006. Odor perception in patients with mood disorders. Journal of Affective Disorders 90, 187-191.

McEwen, B.S., Magarinos, A.M., Reagan, L.P., 2002. Structural plasticity and tianeptine: cellular and molecular targets. European Psychiatry 17, 318-330.

McShane, R.H., Nagy, Z., Esiri, M.M., King, E., Johachim, C., Sullivan, N., Smith, A.D., 2001. Anosmia in dementia is associated with Lewy bodies rather than Alzheimer's pathology. Journal of Neurology, Neurosurgery and Psychiatry 70, 739-743.

Malaspina, D., Coleman, E., 2003. Olfaction and social drive in schizophrenia. Archives of General Psychiatry 60, 578-584.

Malaspina, D., Wray, A.D., Friedman, J.H., Amador, X., Yale, S., Hasan, A., Gorman, J.M., Kaufmann, C.A., 1994. Odor discrimination deficits in schizophrenia: association with eye movement dysfunction. Journal of Neuropsychiatry and Clinical Neurosciences 6, 273-278.

Malaspina, D., Perera, G.M., Lignelli, A., Marshall, R.S., Esser, P.D., Storer, S., Furman, V., Wray, A.D., Coleman, E., Gorman, J.M., Van Heertum, R.L., 1998. SPECT imaging of odor identification in schizophrenia. Psychiatry Research 82, 53-61.

Malaspina, D., Coleman, E., Goetz, R.R., Harkavy-Friedman, J., Corcoran, C., Amador, X., Yale, S., Gorman, J.M., 2002. Odor identification, eye tracking and deficit syndrome schizophrenia. Biological Psychiatry 51, 809-815.

Malberg, J.E., Eisch, A.J., Nestler, E.J., Duman, R.S., 2000. Chronic antidepressant treatment increases neurogenesis in adult rat hippocampus. Journal of Neuroscience 20, 91049110.

Marciani, L., Pfeiffer, J.C., Hort, J., Head, K., Bush, D., Taylor, A.J., Spiller, R.C., Francis, S., Gowland, P.A., 2006. Improved methods for fMRI studies of combined taste and aroma stimuli. Journal of Neuroscience Methods 158, 186-194.

Martin-Soelch, C., Linthicum, J., Ernst, M., 2007. Appetitive conditioning: neural bases and implications for psychopathology. Neuroscience and Biobehavioral Reviews 31, 426440.

Martzke, J.S., Kopala, L.C., Good, K.P., 1997. Olfactory dysfunction in neuropsychiatric disorders: review and methodological considerations. Biological Psychiatry 42, 721-732.

Mesholam, R.I., Moberg, P.J., Mahr, R.N., Doty, R.L., 1998. Olfaction in neurodegenerative disase. A meta-analysis of olfactory functioning in Alzheimer's and Parkinson's diseases. Archives of Neurology 55, 84-90.

Mesulam, M.M., 1998. From sensation to perception. Brain 121, 1013-1052.

Millot, J.L., Brand, G., 2000. Behavioral lateralization during spontaneous smelling tasks. Perceptual \& Motor Skills 90, 444-450.

Mineur, Y.S., Belzung, C., Crusio, W., 2007 Functional implications of neurogenesis impairment following chronic mild stress in mice. Neuroscience, in press.

Moberg, P.J., Turetsky, B.I., 2003. Scent of a disorder: olfactory functioning in schizophrenia. Current Psychiatry Reports 5, 311-319.

Moberg, P.J., Doty, R.L., Turetsky, B.I., Arnold, S.E., Mahr, R.N., Gur, R.C., Bilker, W., Gur, R.E., 1997. Olfactory identification deficits in schizophrenia: correlation with duration of illness. American Journal of Psychiatry 154, 1016-1018.

Moberg, P.J., Agrin, R., Gur, R.E., Gur, R.C., Turetsky, B.I., Doty, R.L., 1999. Olfactory dysfunction in schizophrenia: a qualitative and quantitative review. Neuropsychopharmacology 21, 325-340.

Moberg, P.J., Doty, R.L., Mahr, R.N., Mesholam, R.I., Arnold, S.E., Turetsky, B.I., Gur, R.E., 1997. Olfactory Identification in elderly schizophrenia and Alzheimer's disease. Neurobiology of Aging 18, 163-167. 
Moberg, P.J., Arnold, S.E., Doty, R.L., Kohler, C., Kanes, S., Seigel, S., Gur, R.E., Turetsky, B.I., 2003. Impairment of Odor Hedonics in Men With Schizophrenia. American Journal of Psychiatry 160, 1784-1789.

Moberg, P. J., Arnold, S. E., Doty, R. L., Gur, R. E., Balderston, C. C., Roalf, D. R., Gur, R. C., Kohler, C. G., Kanes, S. J., Siegel, S. J., Turetsky, B. I. (2006). Olfactory functioning in schizophrenia: relationship to clinical, neuropsychological, and volumetric MRI measures. J Clin Exp Neuropsychol 28, 1444-61.

Moskowitz, H.R., Gerbers, C.L., 1974. Functional properties of the olfactory system: psychophysics: dimensional salience of odors. Annals of the New York Academy of Sciences 237, 1-16.

Park, S., Schoppe, S., 1997. Olfactory identification deficit in relation to schizotypy. Schizophrenia Research 26, 191-197.

Pause, B.M., Miranda, A., Göder, R., Aldenhoff, J.B., Ferstl, R., 2001. Reduced olfactory performance in patients with major depression. Journal of Psychiatric Research 35, 271277.

Pause, B.M., Raack, N., Sojka, B., Göder, R., Aldenhoff, J.B., Roman Ferstl, R., 2003. Convergent and divergent effects of odors and emotions in depression. Psychophysiology 40, 209-225.

Phillips, M.L., Drevets, W.C., Rauch, S.L., Lane, R., 2003. Neurobiology of emotion perception I: The neural basis of normal emotion perception. Biological Psychiatry 54, 504-514.

Plailly, J., Amato, T., Saoud, M., Royet, J.P., 2006. Left temporo-limbic and orbital dysfunction in schizophrenia during odor familiarity and hedonicity judgments. NeuroImage 29, 302-313.

Pollatos, O., Albrecht, J., Kopietz, R., Linn, J., Schoepf, V., Kleemann, A.M., Schreder, T., Schandry R., Wiesmann, M., 2007. Reduced olfactory sensitivity in subjects with depressive symptoms. Journal of Affective Disorders 102, 101-108.

Postolache, T.T., Doty, R.L., Wehr, T.A., Jimma, L.A., Han, L., Turner, E.H., Matthews, J.R., Neumeister, A., No, C., Kroger, H., Bruder, G.E., Rosenthal, N.E., 1999. Monorhinal odor identification and depression scores in patients with seasonal affective disorder. Journal of Affective Disorders 56, 27-35.

Postolache, T.T., Wehr, T.A., Doty, R.L., Sher, L., Turner, E.H., Bartko, J.J., Rosenthal, N.E., 2002. Patients With Seasonal Affective Disorder Have Lower Odor Detection Thresholds Than Control Subjects. Archives of General Psychiatry 59, 1119-1122.

Potter, H., Butters, N., 1980. An assessment of olfactory deficits in patients with damage to prefrontal cortex. Neuropsychologia 18, 621-628.

Prince, M., Patel, V., Saxena, S., Maj, M., Maselko, J., Phillips, M.R., Rahman, A., 2007. No health without mental health. The Lancet 370, 859-877.

Purdon, S.E., 1998. Olfactory identification and Stroop interference converge in schizophrenia. Journal of Psychiatry \& Neuroscience 23, 163-171.

Rabin, M.D., Cain, W.S., 1989. Attention and learning in the perception of odor mixtures. In: Laing, D.G., Cain, W.S., McBride, R.L., Ache, B.W. (Eds.), Perception of Complex Smells and Tastes. Academic Press, Sydney, pp. 173-188.

Richardson, J.T.E., Zucco, G.M., 1989. Cognition and olfaction: a review. Psychological Bulletin 105, 352-360.

Roalf, D. R., Turetsky, B. I., Owzar, K., Balderston, C. C., Johnson, S. C., Brensinger, C. M., Gur, R. E., Siegel, S. J., Moberg, P. J. (2006). Unirhinal olfactory function in schizophrenia patients and first-degree relatives. J Neuropsychiatry Clin Neurosci 18, 389-96. 
Roessner, V., Bleich, S., Banaschewski, T., Rothenberger, A., 2005. Olfactory deficits in anorexia nervosa. European Archives of Psychiatry and Clinical Neuroscience 255, 6-9.

Rolls, E.T., Kringelbach M.L., de Araujo, I.E.T., 2003. Different representations of pleasant and unpleasant odours in the human brain. European Journal of Neuroscience 18, 695703.

Rolls, E.T., 2004. Convergence of sensory systems in the orbitofrontal cortex in primates and brain design for emotion. The Anatomical Record Part A: Discoveries in Molecular, Cellular, and Evolutionary Biology 281, 1212-1225.

Rouby, C., Thomas-Danguin, T., 2003. Olfactory performance and health statu: A European survey. Chemical Senses 28, A102-103.

Royet, J.P., Plailly, J., Delon-Martin, C., Kareken, D.A., Segebarth, C., 2003. fMRI of emotional responses to odors: influence of hedonic valence and judgment, handedness, and gender. NeuroImage 20, 713-728.

Rupp, C.I., Fleischhacker, W.W., Kemmler, G., Oberbauer, H., Scholtz, A.W., Wanko, C., Hinterhuber, H., 2005. Various bilateral olfactory deficits in male patients with schizophrenia. Schizophrenia Bulletin 31, 155-165.

Santarelli, L., Saxe, M., Gross, C., Surget, A., Battaglia, F., Dulawa, S., Weisstaub, N., Lee, J., Duman, R., Arancio, O., Belzung, C., Hen, R., 2003. Requirement of hippocampal neurogenesis for the behavioral effects of antidepressants. Science 301, 805-809.

Saoud, M., Hueber, T., Mandran, H., Dalery, J., d'Amato, T., 1998. Olfactory identification deficiency and WCST performance in men with schizophrenia. Psychiatry Research 81, 251-257.

Savic, I., 2001. Processing of odorous signals in humans. Brain Research Bulletin 54, 307312.

Savic, I., Gulyas, B., Larsson, M., Roland, P., 2000. Olfactory functions are mediated by parallel and hierarchical processing. Neuron 26, 735-745.

Sirota, P., Davidson, B., Mosheva, T., Benhatov, R., Zohar, J., Gross-Isseroff, R. (1999). Increased olfactory sensitivity in first episode psychosis and the effect of neuroleptic treatment on olfactory sensitivity in schizophrenia. Psychiatry Res 86, 143-53.

Smutzer, G., Lee, V. M., Trojanowski, J.Q., Arnold, S.E. 1998. Human olfactory mucosa in schizophrenia. The Annals of otology, rhinology, and laryngology 107, 349-355.

Schneider, F., Habel, U., Reske, M., Toni, I., Falkai, P., Shah, N.J., 2007. Neural substrates of olfactory processing in schizophrenia patients and their healthy relatives. Psychiatry Research 155, 103-112.

Schneider, F., Gur, R.E., Alavi, A., Seligman, M.E.P., Mozley, L.H., Smith, R.J., Mozley, P.D., Gur, R.C., 1996. Cerebral blood flow changes in limbic regions induced by unsolvable anagram tasks. American Journal of Psychiatry 153, 206-212.

Seckinger, R.A., Goudsmit, N., Coleman, E., Harkavy-Friedman, J., Yale, S., Rosenfield, P.J., Malaspina, D., 2004. Olfactory identification and WAIS-R performance in deficit and nondeficit schizophrenia. Schizophrenia Research 69, 55-65.

Seidman, L.J., Goldstein, J.M., Goodman, J.M., Koren, D., Turner, W.M., Faraone, S.V., Tsuang, M.T., 1997. Sex differences in olfactory identification and Wisconsin Card Sorting performance in schizophrenia: relationship to attention and verbal ability. Biological Psychiatry 42, 104-115.

Seidman, L.J., Talbot, N.L., Kalinowski, A.G., McCarley, R.W., Faraone, S.V., Kremen, W.S., Pepple, J.R., Tsuang, M.T., 1991. Neuropsychological probes of fronto-limbic system dysfunction in schizophrenia. Olfactory identification and Wisconsin Card Sorting performance. Schizophrenia Research 6, 55-65.

Serby, M.J., Larson, P.M., Kalstein, D., 1990. Olfactory senses in psychosis. Biological Psychiatry 28, 829-830. 
Siegle, G.J., Steinhauer, S.R., Thase, V.A., M.E., Stenger, Carter, C.S., 2002. Can't shake that feeling: event-related fMRI assessment of sustained amygdala activity in response to emotional information in depressed individuals. Biological Psychiatry 51, 693-707.

Siegle, G.J., Thompson, W., Carter, C.S., Steinhauer S.R., Thase, M.E., 2007. Increased amygdala and decreased dorsolateral prefrontal bold responses in unipolar depression: related and independent features. Biological Psychiatry 61, 198-209.

Smutzer, G., Lee, V.M., Trojanowski, J.Q., Arnold, S.E., 1998. Human olfactory mucosa in schizophrenia. Annals of Otology, Rhinology, and Laryngology 107, 349-355.

Solomon, G.S., Petrie W.M., Hart, J.R., Henry B.B., 1998. Olfactory Dysfunction Discriminates Alzheimer's Dementia From Major Depression. Journal of Neuropsychiatry and Clinical Neurosciences 10, 64-67.

Song, C., Leonard, B.E., 2005. The olfactory bulbectomised rat as a model of depression. Neuroscience and Biobehavioral Reviews 29, 627-647.

Stedman, T.J., Clair, A.L., 1998. Neuropsychological, neurological and symptom correlates of impaired olfactory identification in schizophrenia. Schizophrenia Research 32, 23-30.

Szeszko, P. R., Bates, J., Robinson, D., Kane, J., Bilder, R. M. (2004). Investigation of unirhinal olfactory identification in antipsychotic-free patients experiencing a firstepisode schizophrenia. Schizophr Res 67, 219-25.

Thomas-Danguin, T., Rouby, C., Sicard, G., Vigouroux, M., Farget, V., Johanson, A., Bengtzon, A., Hall, G., Ormel, W., De Graaf, C., Rousseau, F., Dumont, J.P., 2003. Development of the ETOC: a European test of olfactory capabilities. Rhinology 41, 142-151.

Turetsky, B.I., Moberg, P.J., Owzar, K., Johnson, S.C., Doty, R.L., Gur, R.E., 2003. Physiologic impairment of olfactory stimulus processing in schizophrenia. Biological Psychiatry 53, 403-411.

Turetsky, B.I., Moberg, P.J., Yousem, D.M., Doty, R.L., Arnold, S.E., Gur, R.E., 2000. Reduced olfactory bulb volume in patients with schizophrenia. American Journal of Psychiatry 157, 828-830.

Turkington, D., Kingdon, D., Weiden, P.J., 2006. Cognitive behavior therapy for schizophrenia. American Journal of Psychiatry 163, 365-373.

Vaidya, J.G., Paradiso, S., Andreasen, N.C., Johnson, D.L., Boles Ponto, L.L., Hichwa, R.D., 2007. Correlation between extraversion and regional cerebral blood flow in response to olfactory stimuli. American Journal of Psychiatry 164, 339-341.

Wagner, G., Sinsel, E., Sobanski, T., Kohler, S., Marinou, V., Mentzel, H.J., Sauer H., Schlosser, R.G.M., 2006. Cortical Inefficiency in Patients with Unipolar Depression: An Event-Related fMRI Study with the Stroop Task. Biological Psychiatry 59, 958-965.

Warner, M. D., Peabody, C. A., Csernansky, J. G. (1990). Olfactory functioning in schizophrenia and depression. Biol Psychiatry 27, 457-8.

Westerwelt, H.J., Ruffolo, J.S., Tremont, G., 2005. Assessing olfaction in neuropsychological exam: The relationship between odor identification and cognition in older adult. Archives of Clinical Neuropsychology 20, 761-469.

Wu, J., Buchsbaum, M.S., Moy, K., Denlea, N., Kesslak, P., Tseng, H., Plosnaj, D., Hetu, M., Potkin, S., Bracha, S., Cotman, C., 1993. Olfactory memory in unmedicated schizophrenics. Schizophrenia Research 9, 41-47.

Yamada, M., Higuchi, T., 2002. Functional genomics and depression research. Beyond the monoamine hypothesis. European Neuropsychopharmacology 12, 235-244.

Yatham, L.N., Malhi, G.S., 2003. Neurochemical brain imaging studies in bipolar disorder. Acta Neuropsychiatrica 15, 381-387. 
Yoshimizu, T., Chaki, S., 2004. Increased cell proliferation in the adult mouse hippocampus following chronic administration of group II metabotropic glutamate receptor antagonist, MGS0039. Biochemical and Biophysical Research Communications 315, 493-496.

Zatorre, R.J., Jones-Gotman, M., Evans, A.C., Meyer, E., 1992. Functional localization and lateralization of human olfactory cortex. Nature 360, 339-340.

Zald, D.H., Pardo, J.V., 1997. Emotion, olfaction, and the human amygdala: amygdala activation during aversive olfactory stimulation. Proceedings of the National Academy of Sciences of the United States of America 94, 4119-4124.

Zald, D.H., Mattson D.L., Pardo, J.V., 2002. Brain activity in ventromedial prefrontal cortex correlates with individual differences in negative affect. Proceedings of the National Academy of Sciences 99, 2450-2454. 


\begin{tabular}{lccc}
\hline Brain areas & Olfaction & Depression & Schizophrenia \\
\hline Olfactory bulbs & + & & \\
Amygdala & + & + & + \\
Hippocampus & & + & + \\
Striatum & & + & + \\
Superior Temporal Gyrus & & & + \\
Planum Temporale & & + & + \\
Parietal Cortex & & & + \\
Corpus Callosum & + & + & + \\
Piriform Cortex & + & + & + \\
Entorhinal Cortex & + & + & + \\
Anterior Cingulate & + & + & + \\
Insula & + & & + \\
Orbitofrontal Cortex & & + & \\
Dorsolateral Prefrontal Cortex & & & + \\
\hline
\end{tabular}

Table 1: + indicates evidence that a precise brain area is involved in olfaction processing or that its morphology or functioning is altered in psychiatric conditions (depression, schizophrenia); ${ }^{1}$ : only in geriatric depression 


\begin{tabular}{|c|c|c|c|c|c|}
\hline & Process & Depression & Schizophrenia & $\begin{array}{l}\text { Alzheimer/ } \\
\text { Dementia }\end{array}$ & Reference \\
\hline Peripheral & $\begin{array}{l}\text { Odour } \\
\text { sensitivity }\end{array}$ & $\begin{array}{c}- \\
+{ }^{\mathrm{a}}: \\
=\end{array}$ & $\begin{array}{l}- \\
+ \\
=\end{array}$ & - & $\begin{array}{l}\text { Serby et al., 1990; Pause et al., 2001; Lombion-Pouthier et al., } \\
2006 \\
\text { Gross-Isseroff et al., 1994;Postolache et al., } 2002 \\
\text { Postolache et al., 1999 } \\
\text { Isseroff et al., 1987, Serby et al., 1990, Sirota et al., 1999; } \\
\text { Rupp et al., 2005a; Rupp et al., 2005b } \\
\text { Bradley, 1984, Sirota et al., } 1999 \\
\text { Kopala et al., 1989; Geddes et al., 1991; Kopala et al., 1993; } \\
\text { Good et al., 1998; Kohler et al. 2001; Moberg et al., 2006; } \\
\text { Plailly et al., 2006 } \\
\text { Mesholam et al., } 1998\end{array}$ \\
\hline Central & $\begin{array}{l}\text { Odour } \\
\text { identification }\end{array}$ & $\begin{array}{l}- \\
=\end{array}$ & - & & $\begin{array}{l}\text { Serby et al., } 1999 \\
\text { Amsterdam et al., 1987; Solomon et al., 1998; Postolache et al., } \\
\text { 1999; Lombion-Pouthier et al., } 2006 \\
\text { Hurwitz et al. 1988; Kopala et al. 1989; Serby et al. 1990; } \\
\text { Seidman et al. 1991; Kopala et al. 1993; Wu et al. 1993; } \\
\text { Houlihan et al. 1994; Kopala et al. 1994; Malaspina et al. 1994; } \\
\text { Kopala et al., 1995; Kopala et al. 1995b; Kopala et al. 1995c; } \\
\text { Brewer et al. 1996; Moberg et al. 1997a; Moberg et al. 1997b; } \\
\text { Seidman et al. 1997; Good et al., 1998; Kopala et al., 1998; } \\
\text { Stedman and Clair, 1998; Saoud et al., 1998; Brewer et al. } \\
\text { 2001; Kohler et al. 2001; Kopala et al. 2001; Hudry et al., } \\
\text { 2002; Coleman et al., 2002; Goudsmit et al., 2003; Malaspina } \\
\text { et al. 2003; Szeszko et al., 2004; Corcoran et al., 2005; Rupp et } \\
\text { al., 2005a; Rupp et al., 2005b; Moberg et al., 2006; Roalf et al., } \\
\text { 2006 } \\
\text { Warner et al., } 1990\end{array}$ \\
\hline
\end{tabular}




\begin{tabular}{|c|c|c|c|c|}
\hline & & & - & Mesholam et al., 1998 \\
\hline $\begin{array}{l}\text { Odour } \\
\text { discrimination }\end{array}$ & $?$ & - & $?$ & $\begin{array}{l}\text { Rupp et al., 2005a; Rupp et al., 2005b } \\
\text { Dunn and Weller, } 1989\end{array}$ \\
\hline $\begin{array}{l}\text { Familiarity/ } \\
\text { recognition }\end{array}$ & $?$ & $\begin{array}{l}- \\
=\end{array}$ & - & $\begin{array}{l}\text { Hudry et al., 2002, Moberg et al., 2003; Rupp et al., 2005b ; } \\
\text { Plailly et al., 2006 } \\
\text { Rupp et al., 2005a } \\
\text { Mesholam et al., } 1998\end{array}$ \\
\hline Intensity & $=$ & $=$ & $?$ & $\begin{array}{l}\text { Pause et al., 2001; Lombion-Pouthier et al., } 2006 \\
\text { Hudry et al., 2002; Moberg et al., 2003; Rupp et al., 2005a; } \\
\text { Rupp et al., 2005b; Plailly et al., } 2006\end{array}$ \\
\hline
\end{tabular}

Table 2: Summary of the different data obtained from the literature. + indicates an improvement of this process in the pathological condition, indicates a deficit, $=$ indicates that this process is not altered in the corresponding disease and indicates that no available data exist. ${ }^{\mathrm{a}}:$ Results obtained after pharmacological treatment 